\title{
Fate of paclitaxel lipid nanocapsules in intestinal mucus in view of their oral delivery
}

This article was published in the following Dove Press journal:

International Journal of Nanomedicine

5 November 2013

Number of times this article has been viewed

\author{
Anne-Claire Groo ${ }^{1,2}$ \\ Patrick Saulnier ${ }^{\prime}$ \\ Jean-Christophe Gimel' \\ Julien Gravier ${ }^{3}$ \\ Caroline Ailhas ${ }^{2}$ \\ Jean-Pierre Benoit ${ }^{1,4}$ \\ Frederic Lagarce ${ }^{1,4}$ \\ 'LUNAM Université, INSERM \\ Ul066 Micro et nanomédecines \\ biomimétiques, Angers, France; \\ ${ }^{2}$ Ethypharm, Grand-Quevilly, France; \\ ${ }^{3}$ Institut Albert Bonniot, INSERM/UJF \\ U823, La Tronche, France; ${ }^{4}$ Pharmacy \\ Department, Angers University \\ Hospital, Angers, France
}

Correspondence: Frederic Lagarce LUNAM Université, INSERM UI066

Micro et nanomédecines biomimétiques,

Bâtiment IBS-IRIS, 4 rue Larrey,

F-49933 Angers, France

Tel +33244688568

Fax +33244688546

Email frederic.lagarce@univ-angers.fr
Abstract: The bioavailability of paclitaxel (Ptx) has previously been improved via its encapsulation in lipid nanocapsules (LNCs). In this work, the interactions between LNCs and intestinal mucus are studied because they are viewed as an important barrier to successful oral delivery. The rheological properties of different batches of pig intestinal mucus were studied under different conditions (the effect of hydration and the presence of LNCs). Fluorescence resonance energy transfer (FRET) was used to study the stability of LNCs in mucus at $37^{\circ} \mathrm{C}$ for at least 3 hours. Diffusion through 223, 446, and $893 \mu \mathrm{m}$ mucus layers of $8.4,16.8$, and $42 \mu \mathrm{g} / \mathrm{mL}$ Ptx formulated as Taxol ${ }^{\circledR}$ (Bristol-Myers Squibb, Rueil-Malmaison, France) or encapsulated in LNCs (Ptx-LNCs) were investigated. The effect of the size of the LNCs on their diffusion was also investigated (range, $25-110 \mathrm{~nm}$ in diameter). Mucus behaves as a non-Newtonian gel with rheofluidifying properties and a flow threshold. The viscous $\left(G^{\prime \prime}\right)$ and elastic $\left(G^{\prime}\right)$ moduli and flow threshold of the two mucus batches varied with water content, but $\mathrm{G}^{\prime}$ remained below $\mathrm{G}^{\prime \prime}$. LNCs had no effect on mucus viscosity and flow threshold. The FRET efficiency remained at $78 \%$ after 3 hours. Because the destruction of the LNCs would lead to a FRET efficiency below $25 \%$, these results suggest only a slight modification of LNCs after their contact with mucus. The diffusion of Taxol ${ }^{\circledR}$ and Ptx-LNCs in mucus decreases if the mucus layer is thicker. Interestingly, the apparent permeability across mucus is higher for Ptx-LNCs than for Taxol ${ }^{\circledR}$ for drug concentrations of 16.8 and $42 \mu \mathrm{g} / \mathrm{mL}$ Ptx $(P<0.05)$. The diffusion of Ptx-LNCs through mucus is not size-dependent. This study shows that LNCs are stable in mucus, do not change mucus rheological properties, and improve Ptx diffusion at low concentrations, thus making these systems good candidates for Ptx oral delivery. The study of the physicochemical interaction between the LNC surface and its diffusion in mucus is now envisioned.

Keywords: diffusion, mucin, nanoparticles, drug absorption, bioavailability

\section{Introduction}

Oral delivery is very convenient but can be very difficult for drugs belonging to class IV of the biopharmaceutical classification system, such as paclitaxel (Ptx). This major lipophilic anticancer drug must be solubilized to be absorbed. This solubilization can be facilitated if the drug is associated with micelles or encapsulated in liposomes or nanoparticles. However, solubility alone is not sufficient; the drug must remain stable in gastrointestinal fluids, and when it reaches absorption areas (mainly the duodenum and jejunum), it needs to overcome the mucus layer to reach the apical side of enterocytes. Once there, it can be transported through the intestinal epithelium by transcellular and paracellular pathways. When a drug uses the transcellular pathway, transport can be active or passive. Finally, enterocytes express P-glycoprotein (P-gp). 
This efflux pump eliminates drugs in cells. After entering the systemic circulation, drugs meet other nonspecific barriers, including the complement system, liver metabolism, spleen filtration, and so on.

Lipid nanocapsules (LNCs) can encapsulate lipophilic drugs such as Ptx and increase their bioavailability. ${ }^{1}$ These nanocapsules can be prepared by a low-energy process ${ }^{2}$ and can be used to encapsulate numerous therapeutic molecules. ${ }^{3}$ These nanovectors are prepared with "generally recognized as safe" products and are compatible with a scalable process. $^{4}$

LNCs have demonstrated in vitro stability in artificial gastrointestinal media. ${ }^{5}$ These nanocarriers have been found to be taken up by Caco- 2 cells, mainly via active endocytic processes, specifically via clathrin-dependent and caveolaedependent transport mechanisms. These mechanisms probably allow transcytosis, and thus improve gastrointestinal crossing of the $\mathrm{drug}^{6}$ and inhibit $\mathrm{P}-\mathrm{gp}^{7,8}$ and have been shown to avoid complement system activation. ${ }^{9}$ However, the fate of LNCs in mucus remains unknown. ${ }^{10}$

Mucus is a complex biological material that lubricates and protects organ surfaces such as the lungs, the gastrointestinal tract, the vagina, the eyes, and the nasal tract. Mucus constitutes an efficient barrier that is often encountered in vivo and has been widely studied during the last few years. There are various mucus models: natural mucus; ${ }^{11,12}$ unpurified type 3 crude mucin; ${ }^{13}$ semipurified ${ }^{14}$ or purified mucin type 2 solutions ${ }^{15}$ synthetic mucus composed with mucin, lipids, and proteins, ${ }^{16}$ and ex vivo tissues such as rat jejunum portion, ${ }^{17}$ rat intestine, ${ }^{18}$ and rat ileum. ${ }^{19}$ Porcine mucus is the most similar to human mucus. Natural mucus is the ideal model, but it presents some inconveniences. First, the difficulty in obtaining it is considerable and often constitutes a crucial limit. Second, its composition, and hence its properties, can vary among batches because of interindividual variability. As a consequence, some people use commercial mucin to prepare mucin solution as a mucus substitute. Two forms of pig gastric mucin are commercialized: type 2, which is a purified mucin, and type 3 , which is an unpurified mucin. The main advantage of these is that the composition is more stable, but the mucus contains various other components such as lipids, proteins, and salts, which may influence drug or particle diffusion. Another possible origin of mucus is cells that secrete mucus. There are cellular models such as HT29MTX, ${ }^{20}$ HT29-FU, ${ }^{21}$ HT29-GlucH, ${ }^{22}$ and co-cultures Caco-2/ HT29-MTX, ${ }^{23}$ Caco-2/HT29-H, ${ }^{24}$ Caco-2/HT29-M6. ${ }^{25}$ Various protocols have been developed to evaluate interactions between particles and mucus; for example, multiple particle tracking, ${ }^{12}$ modified microfiltration device, ${ }^{14}$ mucoadhesion assay, ${ }^{15}$ in vivo experimentation ${ }^{26}$ with radioactivity studies ${ }^{27}$ or pharmacokinetic studies, ${ }^{28}$ binding properties, ${ }^{29}$ side-byside system, ${ }^{30}$ side-on-3-compartment, ${ }^{31}$ diffusion chamber, ${ }^{32}$ modified Transwell-Snapwell ${ }^{\circledR}$ (Sigma-Aldrich, St Louis, MO, USA) diffusion chambers, ${ }^{33}$ modified diffusion cell setup, ${ }^{34}$ fluorescence recovery after photobleaching (FRAP), ${ }^{35}$ radioactivity with 2 syringes, ${ }^{11}$ Transwell ${ }^{\circledR}$ covered by cells, ${ }^{36}$ Transwell ${ }^{\circledR}$ diffusion, ${ }^{19}$ and cell association. ${ }^{37}$ Some techniques are inconvenient to use, such as the complicated equipment used for multiple particle tracking, a fluorophore such as FRAP, or radioactive materials.

The mucus layer covering the surface of the gastrointestinal tract has long been known to be a barrier to exogenous substances, and this needs to be overcome to allow a drug to reach the enterocytes and enter systemic circulation. Interactions between traveling particles and the mucus hydrogel play an important role for their oral availability; it is therefore necessary to know the mucus properties and to understand such interactions to optimize nanocarriers for mucus diffusion.

The aim of the study was, first, to characterize mucus and then to determine the behavior of LNCs in mucus, using stability and diffusion assays.

\section{Materials and methods Materials}

Captex $^{\circledR} 8000$ (tricaprylin) was obtained from Abitec Corp (Colombus, OH, USA) via Unipex (Rueil-Malmaison, France). Lipoid $^{\circledR}$ S75-3 (soy bean lecithin at 70\% phosphatidylcholine and $10 \%$ phosphatidylethanolamine) and Solutol ${ }^{\circledR}$ HS15 (a mixture of free polyethylene glycol 660 and polyethylene glycol 660 hydroxystearate) were obtained from Lipoid Gmbh (Ludwigshafen, Germany) and BASF (Ludwigshafen, Germany), respectively. $\mathrm{NaCl}$ was purchased from Prolabo VWR International (Fontenay-sous-Bois, France). Ptx powder used for LNC formulation was from Teva Pharm (OpavaKomarov, Czech Republic). Injectable solutions of Ptx at $6 \mathrm{mg} / \mathrm{mL}\left(\right.$ Taxol $\left.^{\circledR}\right)$ was obtained from Bristol-Myers Squibb (Rueil-Malmaison, France). Purified water was obtained from a MilliQ185 System (Millipore, Paris, France). Acetonitrile, methanol, dimethyl sulfoxide, and tetrahydrofuran highperformance liquid chromatograph (HPLC) grade were from Fisher Bioblock (Illkirch, France). Acetonitrile, methanol optima, and formic acid optima liquid chromatography-mass spectrometry (LC-MS) grade were from Fisher Bioblock (Illkirch, France). Carbocyanine-based fluorophores, DiI (1,1'-dioctadecyl-3,3,3',3'-tetramethylindocarbocyanine 
perchlorate), and $\operatorname{DiD}\left(1,1^{\prime}\right.$-dioctadecyl-3, 3, 3', $3^{\prime}$ tetramethylindodicarbocyanine perchlorate) were supplied by Invitrogen (Eugene, OR, USA). Phosphate-buffered saline (PBS) was obtained from Lonza (Verviers, Belgium).

\section{Preparation and characterization of blank, Ptx-loaded, or Dil/DiD-loaded LNCs}

LNCs were prepared based on the original process described by Heurtault et al, ${ }^{2}$ with several changes. Briefly, Captex ${ }^{\circledR}$ 8000 (Abitec, Columbus, OH, USA; 29\%, w/w) and Lipoid S75-3 (Lipoid Gmbh (Ludwigshafen, Germany); 1.6\%, w/w) were mixed and heated at $85^{\circ} \mathrm{C}$. Solutol ${ }^{\circledR} \mathrm{HS} 15$ (SigmaAldrich, St Louis, MO, USA; $24.15 \%$, w/w), $\mathrm{NaCl}$ (1.77\%, $\mathrm{w} / \mathrm{w})$, and water $(43.48 \%, \mathrm{w} / \mathrm{w})$ were added and homogenized under magnetic stirring. Three cycles of progressive heating and cooling between $70^{\circ} \mathrm{C}$ and $90^{\circ} \mathrm{C}$ were then carried out and followed by an irreversible shock induced by dilution with $2^{\circ} \mathrm{C}$ purified water $(73 \%, \mathrm{v} / \mathrm{v})$ added to the mixture at $78^{\circ} \mathrm{C}$. Slow magnetic stirring was then applied to the suspension of LNCs for 5 minutes at room temperature. To prepare Ptx-loaded LNCs, $29.3 \mathrm{mg}$ of Ptx was dissolved in Captex ${ }^{\circledR}$ 8000 in the presence of ethanol; the solvent was evaporated at $80^{\circ} \mathrm{C}$ before use. To prepare DiI/DiD-loaded LNCs, DiI and DiD were dissolved in ethanol, which was then evaporated. The resulting solution was finally dissolved in Captex 8000 to obtain solutions at 4 and $3 \mathrm{mM}$, respectively. LNCs were then prepared as described previously. The size of the nanoparticles was measured by dynamic light scattering on a Zetasizer Nano series DTS 1060 (Malvern Instruments SA, Worcestershire, United Kingdom). To determine the Ptx encapsulation ratio, LNCs were filtered using a Minisart ${ }^{\circledR} 0.2 \mu \mathrm{m}$ filter (Vivascience AG, Hanover, Germany) after fabrication to eliminate Ptx crystals that were not encapsulated. Three samples of filtrate were prepared by dissolution of an exact quantity of LNCs dispersion in a 96/4 (v/v) methanol/tetrahydrofuran solution and then filtrated on a Minisart ${ }^{\circledR} 0.2 \mu \mathrm{m}$ filter to eliminate the residual components of the LNCs. A $15 \mu \mathrm{L}$ aliquot of each filtrate was injected in triplicate onto an HPLC column. Chromatography was performed using a Waters 717 plus autosampler, Waters 600 controller, and Waters 2487 Dual Absorbance Spectrometer (Waters SA, Saint-Quentin-enYvelynes, France) with an XTerra ${ }^{\circledR}$ C18-ODB $150 \times 4.60 \mathrm{~mm}$ column (Waters, Milford, Ireland) and an ultraviolet detector set at $227 \mathrm{~nm}$. The flow rate was set to $1 \mathrm{~mL} /$ minute. The gradient was obtained by mixing a proportion of phase $\mathrm{A}$ (water) and phase $\mathrm{B}$ (acetonitrile). Initially, the mobile phase composition was $50 \% \mathrm{~B}$; a linear gradient was applied to reach a composition of $85 \% \mathrm{~B}$ after 7 minutes, maintained for
2 minutes, and then returned to the initial conditions. Quantification was achieved by comparing observed peak area ratios of Ptx in the samples with a calibration curve obtained under the same experimental conditions. Linearity was observed in the range from 39.0 to $390.2 \mathrm{mg} / \mathrm{L}$, with a correlation coefficient above 0.99 . The detection limit was $10.0 \mathrm{mg} / \mathrm{L}$, and the quantification limit was $20.0 \mathrm{mg} / \mathrm{L}$. The mean drug payload (milligrams of Ptx per gram of LNCs dispersion) of each batch of LNC dispersion and the standard deviation were calculated from three samples. The encapsulation efficiency (\%) was determined by dividing the measured drug payload by the theoretical drug payload (calculated from the exact amounts of each component of the formulation).

\section{Preparation of mucus}

The pigs were fasted overnight. The duodenum and jejunum of freshly slaughtered pigs were isolated and cut open by the veterinary surgeon based at ONIRIS (Nantes, France). The mucosal surfaces were washed with double-distilled water. Mucus was gently scraped with a spatula. The collected mucus was pooled, frozen in aliquots, and kept at $-20^{\circ} \mathrm{C}$ until further use. The mucus was thawed for approximately 15 minutes at room temperature before experimentation.

\section{Characterization of mucus Water content}

The $\mathrm{pH}$ of native mucus samples was approximately neutral ( $7.0 \pm 0.5)$. To check the $\mathrm{pH}, \mathrm{pH}$ paper was used. The water content was determined by freeze drying and desiccation. The desiccation assay was carried out according to the European Pharmacopoeia (ie, a heating cycle lasting 4 hours at $100^{\circ} \mathrm{C}$ and a cooling period of 45 minutes in a desiccator, then 1 hour cycles at $100^{\circ} \mathrm{C}$, followed by 45 minutes of cooling until mass stabilization was achieved). Water content was calculated by weighing before and after lyophilization $(\mathrm{n}=3)$. Next, residual water was checked by heating up at $100^{\circ} \mathrm{C}$ over the course of 4 hours and following cycles at $100^{\circ} \mathrm{C}$ over the course of 1 hour until mass stabilization.

\section{Rheological characterization of mucus/viscosimetry}

Samples for rheological characterization were stored at $-20^{\circ} \mathrm{C}$ until cone-and-plate rheometry (kinexus pro Rheometer, Malvern, Worcestershire, United Kingdom) was performed. The rheometer was set to steady mode, and specimens warmed at $25^{\circ} \mathrm{C}$ or $37^{\circ} \mathrm{C}$ were subjected to shear deformation at controlled shear rates to measure the shear viscosity of mucus. Dynamic oscillatory measurements were 
performed with controlled deformation at $25^{\circ} \mathrm{C}$. Storage and loss moduli were measured as a function of both deformation and frequency. The linear viscoelastic region was determined with a strain sweep under a strain amplitude from $0.01 \%$ to $100 \%$ at a frequency interval from 0.1 to $100 \mathrm{~Hz}$. Frequency sweeps were performed over a frequency interval from 0.1 to $100 \mathrm{~Hz}$ at a constant strain amplitude (5\%). The linear region was the region of strain whereby no yielding of the substances occurs, and the determination of the characteristic relaxation time can occur from the strain sweep tested.

Shear viscosity is measured as a function of shear stress. Unmodified mucus batches ( $\mathrm{n}=2)$, mucus supplemented with water and mucus containing LNCs were studied to evaluate LNC addition and the hydration effect.

\section{LNC stability in mucus}

\section{Absorbance and fluorescence spectra}

Emission spectra were recorded using a Perkin-Elmer LS55 fluorometer and the PTP-1 fluorescence Peltier system (PerkinElmer, Waltham, MA, USA), respectively, to maintain the temperature at $37^{\circ} \mathrm{C}$ when relevant. Absorbance spectra were recorded on a Thermo Scientific Evolution 201 UVVisible spectrophotometer (Thermo Fisher Scientific Inc., Waltham, MA, USA). All measurements were performed using 3-window, $100 \mu \mathrm{L}$ quartz cuvettes. Typical dye concentrations of $1 \mu \mathrm{M}$ were used for measurements.

\section{FRET calculation}

Experimentally, the FRET efficiency can be calculated by measuring the relative fluorescence intensity of the donor in the absence or in the presence of the acceptor. Absorbance and emission spectra of DiI-loaded LNCs (noted $A_{D}$ and $F_{D}$, respectively) and DiD-loaded LNCs $\left(A_{A}\right.$ and $\left.F_{A}\right)$ and FRETloaded LNCs $\left(A_{F R E T}\right.$ and $\left.F_{F R E T}\right)$ were measured. All absorption spectra were corrected for scattering, and all emission spectra were recorded with an excitation level corresponding to the donor dye (540 nm). Emission spectra and corrected absorption spectra of the FRET nanoparticles were then fitted using the reference spectra obtained with donor and acceptor alone by optimizing Equations 1 and 2:

$$
A_{F R E T}(\lambda)=x_{D} \cdot A_{D}(\lambda)+x_{A} \cdot A_{A}(\lambda)
$$

and

$$
F_{F R E T}(\lambda)=y_{D} \cdot F_{D}(\lambda)+y_{A} \cdot F_{A}(\lambda)
$$

where $x_{D}$ and $x_{A}$ are the fitting terms associated with donor and acceptor absorbance spectra and $y_{D}$ and $y_{A}$ are the fitting terms associated with donor and acceptor spectra. The classical formula for FRET efficiency is

$$
E=1-\frac{F_{D A}}{F_{D}},
$$

where $F_{D A}$ is the fluorescence of the donor in the presence of the acceptor (which is $y_{D}$ times the fluorescence of the DiI reference) and $F_{D}$ is the fluorescence of the donor in the absence of the acceptor (in the absence of FRET, this value should be $x_{D}$ times the fluorescence of the DiI reference). The experimental FRET efficiency is therefore calculated according to Equation 4:

$$
E=1-\frac{y_{D} \cdot F_{D}}{x_{D} \cdot F_{D}}=1-\frac{y_{D}}{x_{D}} .
$$

Mucus stability measurements were performed after mixing $5 \mu \mathrm{L}$ FRET-LNC with $200 \mu \mathrm{L}$ mucus at $37^{\circ} \mathrm{C}$. Because the mucus was too diffusive to enable reliable absorbance measurements, the FRET-LNC efficiency was measured in PBS at $37^{\circ} \mathrm{C}$, as described earlier. Then the calculated efficiency value was used as a reference for $t=0: y_{D}$, which was optimized for the $t_{0}$ spectrum, using Equation 2. Then $x_{D}$ was calculated using Equation 3, optimized $y_{D}$, and the value of FRET efficiency in intact $\mathrm{LNCs}$ at $37^{\circ} \mathrm{C}$ in PBS. Subsequent efficiency measurements for $t>0$ were made using Equation 3, the fitted $y_{D}$ value, and the calculated $x_{D}$ value.

\section{Diffusion through the mucus}

The transport of different formulations of Ptx:Taxol ${ }^{\circledR}$ and Ptx-loaded LNCs was studied from the donor to the receptor compartment, using a Transwell ${ }^{\circledR}$ system. The diffusion cell set-up consisted of polycarbonate Snapwell ${ }^{\circledR}$ inserts that have surface areas of $1.12 \mathrm{~cm}^{2}$. The receptor compartment contained $1.5 \mathrm{~mL}$ PBS (10 mM phosphate buffer, $2.7 \mathrm{mM} \mathrm{KCl}, 137 \mathrm{mM}$ $\mathrm{NaCl}$ at $\mathrm{pH} 7.5)$. The test solutions were diluted in $\mathrm{PBS}$ at 8.4, 16.8 , and $42 \mu \mathrm{g} / \mathrm{mL}$ Ptx concentrations. Mucus layers were put on the Snapwell ${ }^{\circledR}$ inserts at a volume of 25,50 , and $100 \mu \mathrm{L}$ to obtain a mucus thickness of 223,446 , and $893 \mu \mathrm{m}$, respectively. The experiment was started by gently adding $0.5 \mathrm{~mL}$ of the dispersion to be analyzed in the donor compartment, on the mucus layer. Then the Transwell ${ }^{\circledR}$ system was incubated at $37^{\circ} \mathrm{C}$. After 2 or 4 hours of incubation, samples were taken from the receptor compartment, and the Ptx content was determined by LC-MS/MS (liquid chromatography-tandem mass spectrometry). The apparent permeability coefficient $\left(P_{\text {app }}\right)$, expressed in centimeters per second, was calculated according to the following equation: ${ }^{38,39}$ 


$$
P_{a p p}=\frac{d Q}{\mathrm{dt} * \mathrm{~A}^{*} \mathrm{C}_{0}},
$$

where $d Q / \mathrm{dt}$ is the rate of drug appearance in the receptor compartment $\left(\mu \mathrm{g} \cdot \mathrm{s}^{-1}\right), \mathrm{C}_{0}$ is the initial concentration in the donor compartment $\left(\mu \mathrm{g} \cdot \mathrm{mL}^{-1}\right)$, and $\mathrm{A}$ is the surface area of the monolayer $\left(\mathrm{cm}^{2}\right)$.

\section{Ptx analysis by LC-MS/MS}

Chromatography was performed using a Waters Alliance ${ }^{\circledR}$ 2695 system (Waters SA, Saint-Quentin-en-Yvelines, France) with an Uptisphere ${ }^{\circledR}$ C18-ODB $150 \times 2.0 \mathrm{~mm}$, $5 \mu \mathrm{m}$ column (Interchrom, Montluçon, France). The mobile phase consisted of phase A $(0.1 \%$ formic acid in water $)$ and phase $\mathrm{B}(0.1 \%$ formic acid in methanol). Under initial conditions, the mobile phase composition was $30 \% \mathrm{~B}$; a linear gradient was applied to reach a composition of 98\% B after 5 minutes, maintained for 0.5 minutes, and then set to return to the initial conditions. The flow rate was $0.3 \mathrm{~mL} / \mathrm{min}$. The total HPLC effluent was directed into a Quattro Micro ${ }^{\circledR}$ triple quadruple mass spectrometer (Waters SA). Ionization was achieved using a turbo ion spray in positive ion mode. The mass spectrometer operated in multiple reaction monitoring mode. The $(\mathrm{M}-\mathrm{H})$ $+\mathrm{m} / \mathrm{z}$ transitions for each compound were $854.1 \rightarrow 286.1$ and $876.3 \rightarrow 308.1$ (sodium adduit). A typical retention time of Ptx was found to be 6.41 minutes. Quantification was achieved with QuantLynx ${ }^{\circledR}$ (Waters SA) by comparison of the observed peak area ratios of Ptx samples to a calibration curve obtained under the same conditions. The range of linear response was $0.015-7.2 \mu \mathrm{g} / \mathrm{mL}$, the lower limit of detection was $0.015 \mu \mathrm{g} / \mathrm{mL}$, and the lower limit of quantification was $0.75 \mu \mathrm{g} / \mathrm{mL}$.

\section{Statistical analysis}

Results were expressed as mean values \pm SEM. A Student's $t$-test was used for statistical comparison/analysis, and $P<0.05$ was considered statistically significant.

\section{Results}

\section{Preparation and characterization of blank, Ptx-loaded, or Dil/DiD-loaded LNCs}

Four sizes of LNCs were obtained by varying the manufacturing process parameters (Table 1). The resulting physical characteristics of the LNCs are presented in Table 2. The mean diameter ranged from $27.0 \pm 0.0 \mathrm{~nm}$ to $118.3 \pm 2.1 \mathrm{~nm}$ for Ptx-LNCs. The zeta potentials
Table I Composition of 3 batches of lipid nanocapsules used to obtain different sizes

\begin{tabular}{llll}
\hline Constituents & Amount $\mathbf{( g )}$ & & \\
\cline { 2 - 4 } & $\begin{array}{l}\text { 25-LNC of } \\
\text { paclitaxel }\end{array}$ & $\begin{array}{l}\text { 55-LNC of } \\
\text { paclitaxel }\end{array}$ & $\begin{array}{l}\text { I I } \mathbf{0 - L N C ~ o f ~} \\
\text { paclitaxel }\end{array}$ \\
\hline Lipoid $^{\otimes} 75-3$ & 0.067 & 0.067 & 0.067 \\
Captex $^{\otimes} 8000$ & 0.68 & 1.2 & 1.4 \\
Solutol $^{\circledR} \mathrm{HSI5}$ & 1.6 & 1 & 0.5 \\
$\mathrm{NaCl}$ & 0.073 & 0.073 & 0.073 \\
Purified water & 1.72 & 1.8 & 2.1 \\
Purified water at $2^{\circ} \mathrm{C}$ & $1 \mathrm{I} .2$ & 11.2 & 11.2 \\
\hline
\end{tabular}

Abbreviation: LNC, lipid nanocapsules.

were positive for DiI/DiD-loaded LNCS and negative for blank LNCs and Ptx-loaded LNCs. For all formulations, the polydispersity index was less than 0.2 , which demonstrates the monodispersity of the preparations. The drug payload was from $1.27 \pm 0.00$ to $1.86 \mathrm{mg} / \mathrm{g}$ of formulation (Table 2).

\section{Characterization of mucus Water content}

The water content was different in both mucus batches. Batch 1 was composed of $90.8 \% \pm 0.1 \%$ water, whereas batch 2 was made of $87.6 \% \pm 0.1 \%$ water.

\section{Rheological characterization of mucus}

Figure 1 illustrates the shear viscosity vs shear rate profiles of 2 mucus batches at $25^{\circ} \mathrm{C}$ and $37^{\circ} \mathrm{C}$. The shear viscosity progressively decreased (shear thinning). Batch 2 of mucus at $25^{\circ} \mathrm{C}$ and $37^{\circ} \mathrm{C}$ and batch 1 (but only at $37^{\circ} \mathrm{C}$ ) showed a

Table 2 LNC characteristics: particle size, polydispersity, and zeta potential of blank and paclitaxel or Dil/DiD-loaded lipid nanocapsules, and drug payload of paclitaxel-loaded lipid nanocapsules

\begin{tabular}{lclll}
\hline $\begin{array}{l}\text { Batch } \\
\text { name }\end{array}$ & $\begin{array}{l}\text { Mean } \\
\text { particle } \\
\text { size }(\mathbf{n m})\end{array}$ & $\begin{array}{l}\text { Polydispersity } \\
\text { index }\end{array}$ & $\begin{array}{l}\text { Zeta } \\
\text { potential } \\
(\mathbf{m V})\end{array}$ & $\begin{array}{l}\text { Drug } \\
\text { payload } \\
(\mathbf{m g} / \mathbf{g})\end{array}$ \\
\hline $\begin{array}{l}\text { Blank } \\
55-L N C\end{array}$ & $55.9 \pm 0.6$ & $0.042 \pm 0.007$ & $-9.4 \pm 0.8$ & - \\
$\begin{array}{l}25-L N C \text { of } \\
\text { paclitaxel }\end{array}$ & $27.0 \pm 0.0$ & $0.062 \pm 0.007$ & $-4.8 \pm 0.5$ & $1.79 \pm 0.03$ \\
$\begin{array}{l}55-L N C \text { of } \\
\text { paclitaxel }\end{array}$ & $54.7 \pm 0.4$ & $0.038 \pm 0.008$ & $-6.7 \pm 1.1$ & $1.86 \pm 0.01$ \\
$\begin{array}{l}\text { II0-LNC of } \\
\text { paclitaxel }\end{array}$ & $118.3 \pm 2.1$ & $0.071 \pm 0.016$ & $-5.4 \pm 0.4$ & $1.27 \pm 0.00$ \\
$\begin{array}{l}55-L N C \text { of } \\
\text { Dil/DiD }\end{array}$ & $58.0 \pm 2.1$ & $0.166 \pm 0.081$ & $15.9 \pm 1.8$ & - \\
\hline
\end{tabular}

Abbreviations: DiD, I,I'-dioctadecyl-3,3,3, $3^{\prime}$-tetramethylindodicarbocyanine perchlorate; Dil, I, I'-dioctadecyl-3,3,3',3'-tetramethylindocarbocyanine perchlorate; LNC, lipid nanocapsules. 
A

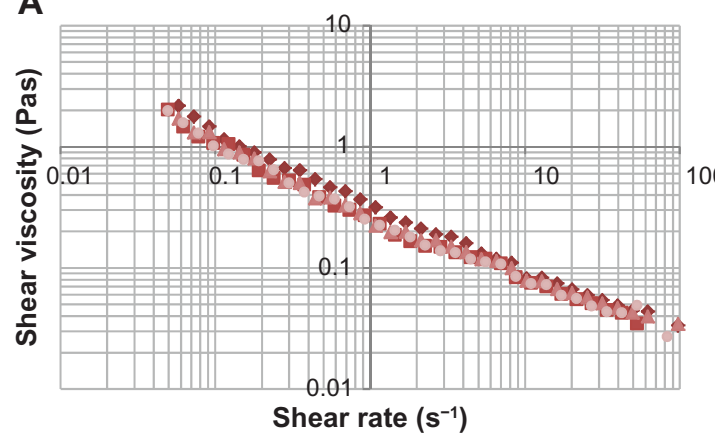

C

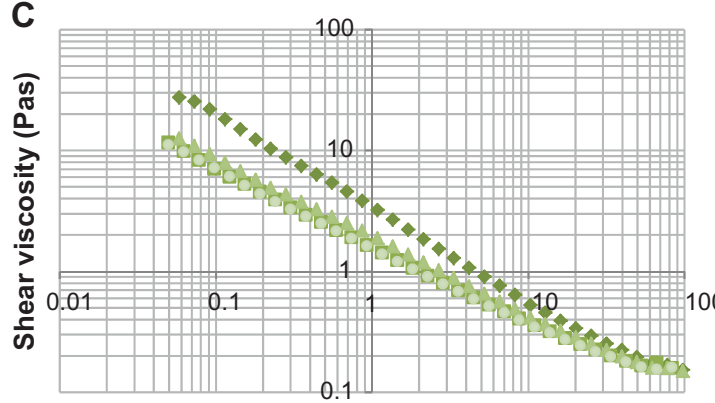

Shear rate $\left(\mathbf{s}^{-1}\right)$
B

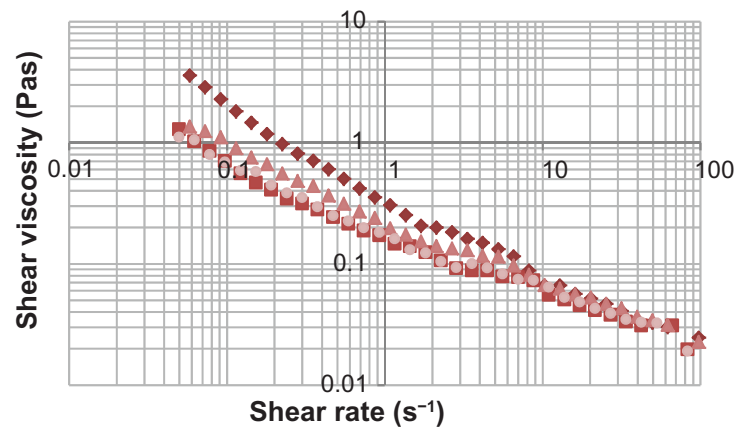

D

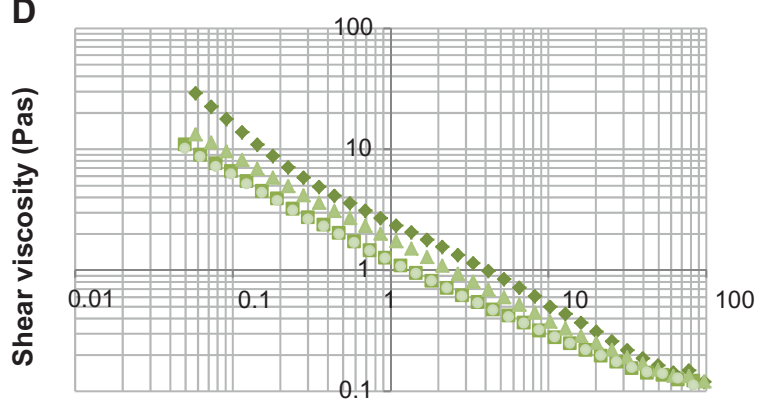

Shear rate $\left(\mathbf{s}^{-1}\right)$

Figure I Viscosity of batch I at $25^{\circ} \mathrm{C}(\mathbf{A})$ and at $37^{\circ} \mathrm{C}(\mathbf{B})$. Viscosity of batch 2 at $25^{\circ} \mathrm{C}(\mathbf{C})$ and at $37^{\circ} \mathrm{C}(\mathbf{D})$.

Note: Ramp $\mathrm{I}$ is symbolized by diamonds, ramp 2 by squares, ramp 3 by triangles and ramp 4 by circles.

thixotropic property. The mucus behaved as a shear-thinning (non-Newtonian) gel and displayed a flow threshold at $37^{\circ} \mathrm{C}$ (and at $25^{\circ} \mathrm{C}$ for batch 2).

Elastic $\left(G^{\prime}\right)$ and viscous $\left(G^{\prime \prime}\right)$ moduli of the two mucus batches are presented as functions of oscillatory frequencies plotted against frequency (Figure 2).

For the two mucus batches, the elastic modulus $\left(\mathrm{G}^{\prime}\right)$ was greater than the viscous modulus $\left(\mathrm{G}^{\prime \prime}\right)$. Nevertheless, the values of batch 2 for both moduli were higher than those of batch 1 .

These rheograms showed that small variations in the amount of water in the mucus could produce marked changes in its rheological properties (Figure 3).

The rheogram of mucus is the same with water and with LNCs. As a consequence, the LNCs did not influence mucus rheological properties (Figure 3).

\section{Stability study}

Three different batches of LNCs were placed in mucus at $37^{\circ} \mathrm{C}$, and the FRET efficiency was studied for 3 hours. The FRET efficiency of all batches decreased slightly (Figure 4). After 3 hours in mucus at $37^{\circ} \mathrm{C}, \mathrm{LNCs}$ lost $22 \%$ of their initial FRET efficiency.

\section{Diffusion through the mucus}

At a concentration of $16.8 \mu \mathrm{g} / \mathrm{mL}$, Taxol $^{\circledR}$ diffusion at 4 hours was not significantly different $(P>0.05)$ through the 2 mucus batches (Figure 5), despite their different rheological properties. The diffusion of Taxol ${ }^{\circledR}$ and LNCs decreased with mucus layer thickness (Figures 5 and 6). The LNC diffusion through the Transwell ${ }^{\mathbb{}}$ system without mucus depended on LNC size in this size range (Figure 6). The diffusion of $110 \mathrm{~nm}$ LNCs was different through the Transwell ${ }^{\circledR}$ system from the diffusion of smaller LNCs; in fact, they were slowed down by the Transwell ${ }^{\circledR}$ membrane. Smaller LNCs (25 and $55 \mathrm{~nm}$ ) presented the same diffusion through the Transwell ${ }^{\circledR}$ system and mucus.

The diffusion of $55 \mathrm{~nm} \mathrm{LNCs}$ or Taxol ${ }^{\circledR}$ at three different concentrations was studied through the mucus layer (Figure 7A). Taxol ${ }^{\circledR}$ diffusion through mucus was too low, at $8.4 \mu \mathrm{g} / \mathrm{mL}$, and the diffused Ptx quantity was out of quantification limits; apparent permeability was thus considered unquantifiable in this case.

Because Taxol ${ }^{\circledR}$ and LNC diffusions were found to be different in the absence of mucus and to depend on their concentration, their diffusion through the mucus can only be compared by using a permeability ratio (Figure 7B). At high concentrations, LNC diffusion through mucus was 


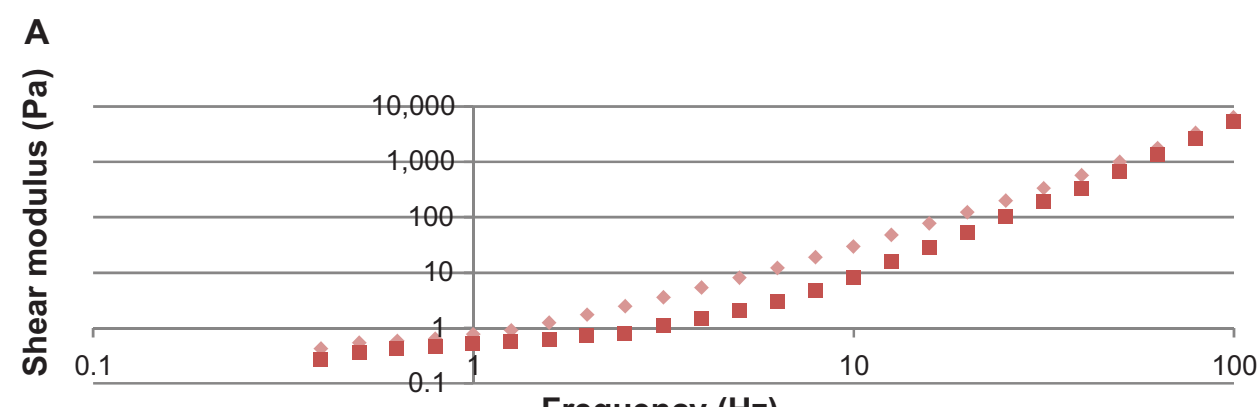

Frequency $(\mathrm{Hz})$

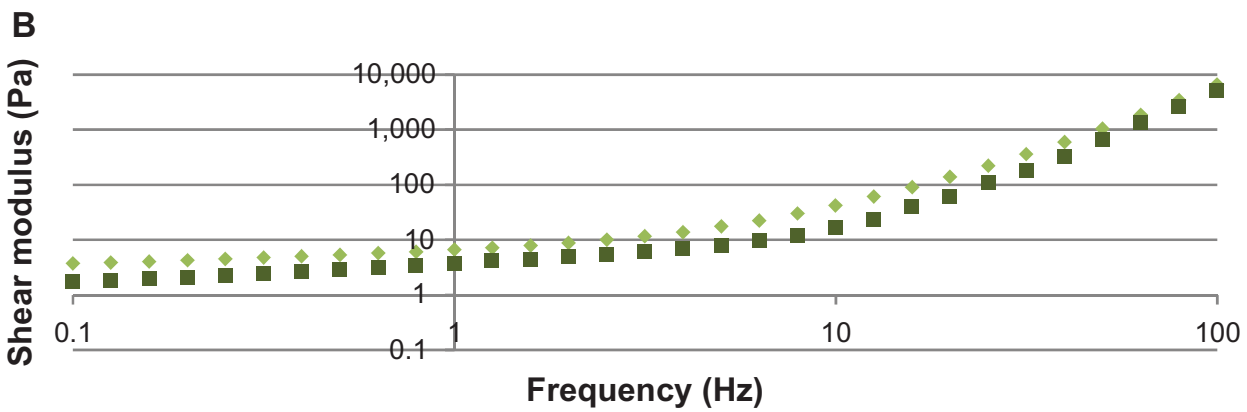

Figure 2 Frequency sweep at $25^{\circ} \mathrm{C}$ with $5 \%$ amplitude of batch I (A) and batch 2 (B). Shear moduli (Pa): Elastic components (diamonds) and viscous components (squares).

enhanced and the permeability ratio was significantly reduced $(P<0.05)$.

At 16.8 and $42 \mu \mathrm{g}$ Ptx $/ \mathrm{mL}$, the effect of mucus on LNC diffusion was lower than that of Taxol ${ }^{\circledR}$ diffusion $(P<0.05)$.

\section{Discussion}

Because mucus is a barrier that has to be crossed before absorption in the case of oral delivery, the fate of the drug and drug product in mucus has to be studied. However, it has been observed that the methodology used for these studies had an effect on the results. Models displayed different properties, and thus did not constitute an equivalent barrier for molecules and particles. For example, a study showed that rhodamine permeation was significantly different in mucin solution and in an artificial cystic fibrosis mucus model, because of the differences in the mucus model composition. ${ }^{34}$ In our study, the closest model to human intestinal mucus model was chosen (ie, pig intestinal mucus). This model contained principally water, mucin, lipids, and proteins, making it more complex than mucin used alone or artificial mucus. ${ }^{40}$ To limit the slight interindividual variability in composition and mucin structure,

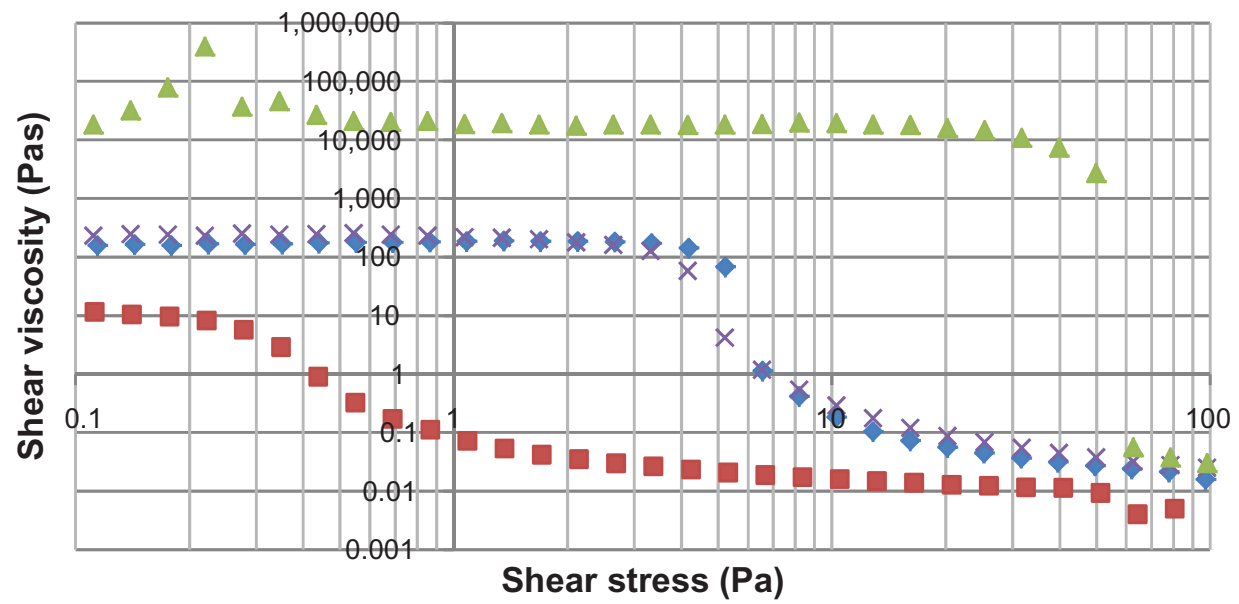

Figure 3 Effect of lipid nanocapsules or water addition on the mucus flow threshold at $37^{\circ} \mathrm{C}$. Shear viscosity of mucus batch I (red squares), mucus batch 2 with lipid nanocapsules (blue diamonds), mucus batch 2 with water $(X)$, and mucus batch 2 (green triangle). 


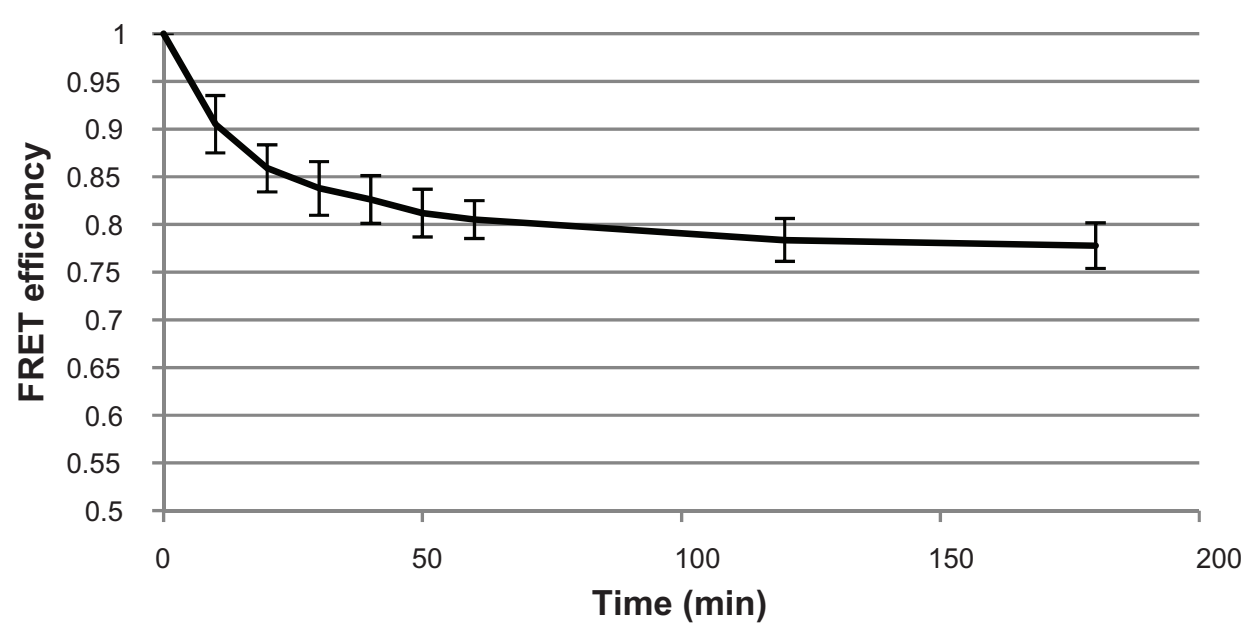

Figure 4 Fluorescence resonance energy transfer (FRET) efficiency evolution over the course of 3 hours. Note: Data are shown as mean \pm standard deviation $(n=3)$.

2 batches were collected and characterized and then pooled to obtain a standard material for further testing. The pig mucus used in our study had a hydration level close to what has been previously described in the literature ${ }^{41}$ with similar rheological properties: $^{42}$ it is a shear-thinning (non-Newtonian) gel, and its viscosity is in the same size order.

After characterization of the mucus used and a comparison of its properties to other models, we were able to perform stability and diffusion studies with blank and Ptx-loaded LNCs, respectively. To our knowledge, the present article describes the first stability study of nanoparticles after contact with intestinal mucus. A previous cell transport study from our group showed that LNCs improved Ptx transport throughout human intestinal epithelial cells by a factor of three, ${ }^{6}$ but in this Caco- 2 model, no mucus was present.
Therefore, we had to check that particles remained intact after contact with mucus. To do so, the FRET technique was used. This technique is valid for stability studies if the fluorescent probes remain associated in the nanocapsules as long as they are intact. Thus, a major loss of FRET efficiency suggests that the nanocarrier has been destroyed.

In the present study, DiD and Dil were used as probes because of their stability in LNCs, as has been previously observed in vivo and in vitro. ${ }^{43}$ In the concentration range used, DiI and DiD brought a positive charge to the nanocapsules. It was relevant to use small nanocapsule quantities in mucus to study their stability in worst-case conditions, and thus we had to encapsulate a high amount of dyes, which unfortunately had an effect on the charge. We obtained a positive charge of $+8 \mathrm{mV}$ after encapsulation of each dye

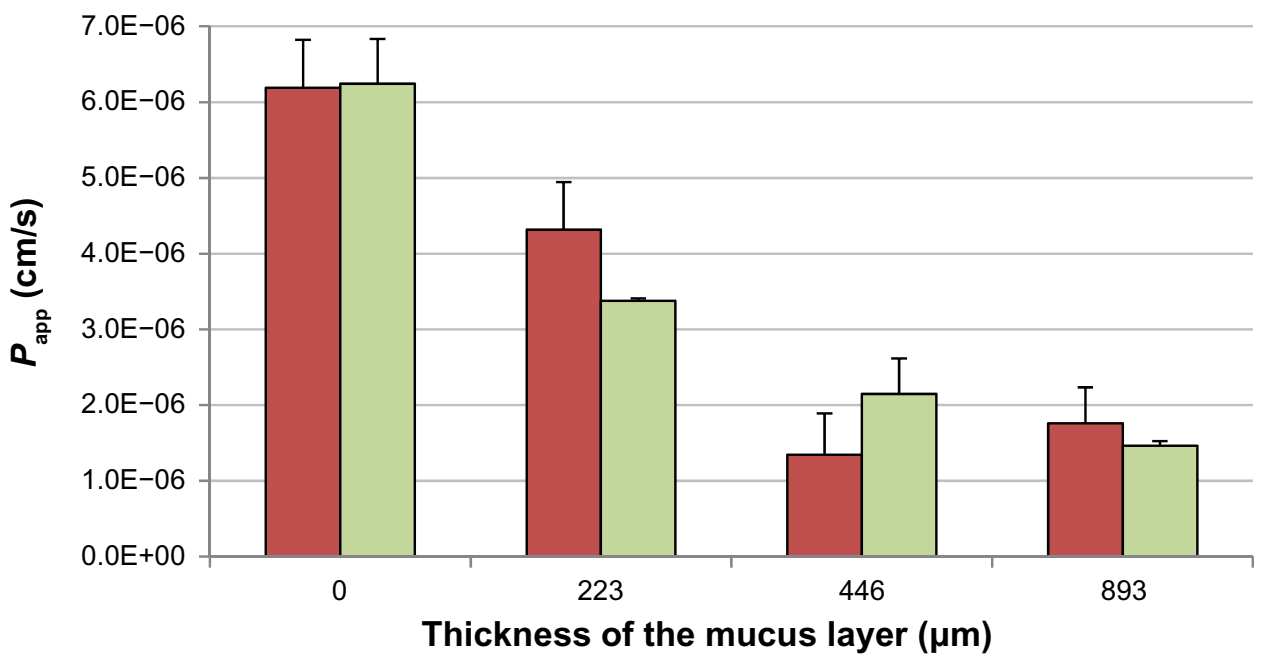

Figure 5 Comparison of $\mathrm{Taxol}^{\circledR}(16.8 \mu \mathrm{g} / \mathrm{mL})$ diffusion after 4 hours through mucus batch I (red bars) and mucus batch 2 (green bars).

Note: Data are shown as mean \pm standard error of the mean $(n=3)$.

Abbreviation: $P_{\text {app }}$, apparent permeability. 


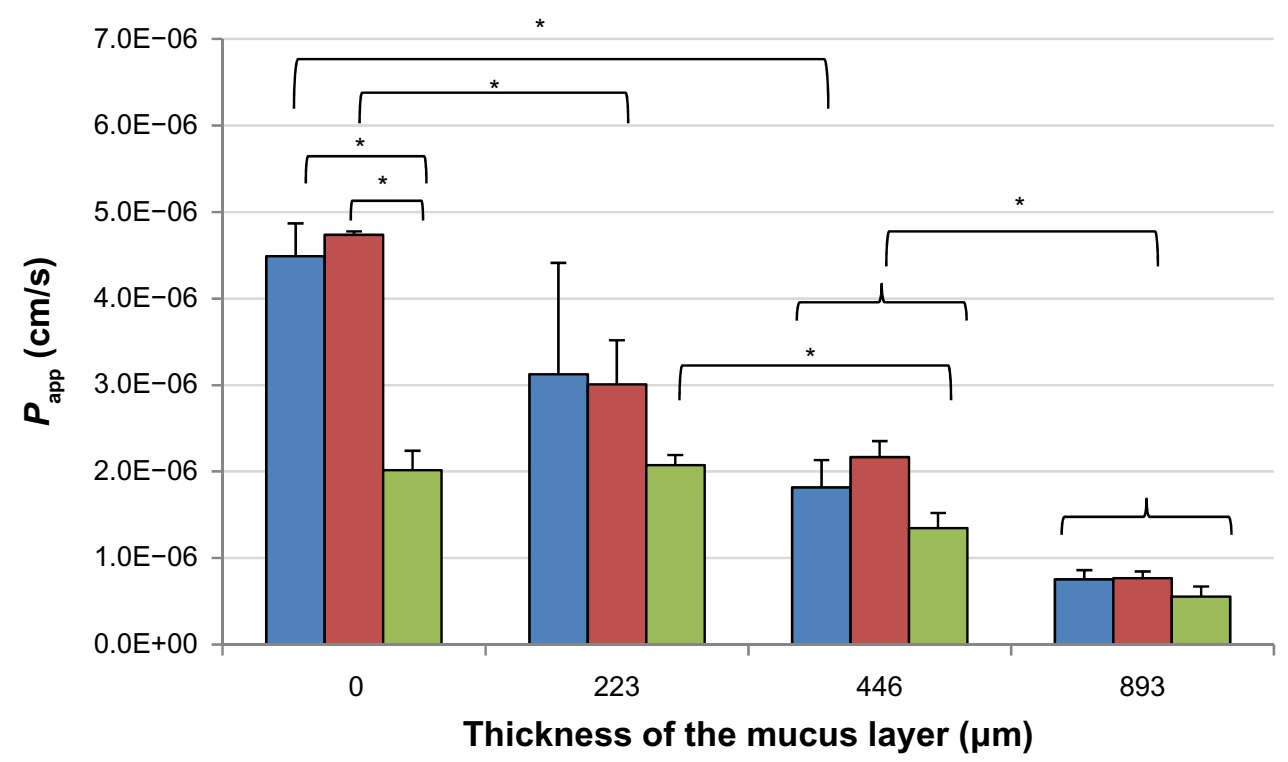

Figure 6 Diffusion of LNCs as a function of their size ( $16.8 \mu \mathrm{g} / \mathrm{mL}$ ) after 2 hours; 25-nm LNCs (blue bars), 55-nm LNCs (red bars), and I I0-nm LNCs (green bars). Notes: Data are shown as mean \pm standard error of the mean $(n=3) ; * P<0.05$.

Abbreviations: LNC, lipid nanocapsule; $P_{\text {app }}$, apparent permeability.

separately, and the encapsulation of both dyes brought a charge of $+15 \mathrm{mV}$, giving evidence that the positive charge is linked to the presence of the dyes in the nanocapsules. As explained earlier, it was not possible to encapsulate a high enough amount of dye without changing LNC charges. This modification may have an effect on diffusion, but in this particular stability experiment, the diffusion process has a relatively low effect on stability in comparison with other phenomena such as lipid exchange or tensioactive modification after contact with mucin or phospholipids present in mucus. LNCs are mixed with mucus at the start of experiment to limit the effect of diffusion. In fact, our experiment uses diluted LNCs in mucus, and thus the experimental protocol is designed to explore LNC stability after contact in mucus, but not possible fusion between LNCs after a diffusion process. In our study, a slight loss of FRET efficiency $(<25 \%)$ was not considered a sign of LNC destruction but, rather, an increase of LNC size after contact with mucus (swelling). In fact, FRET efficiency depended on the concentration of DiD and DiI in the LNC core, and it was calculated that a FRET loss of $22 \%$ in our study may be a result of a diameter increase of $5 \mathrm{~nm}$.

After assessing that LNCs were stable in mucus, it was relevant to measure their diffusion across this barrier. As stated before, LNC transport was only tested throughout Caco- 2 cell monolayers. ${ }^{6} \mathrm{~A}$ diffusion study in mucus is complementary and necessary to predict bioavailability. A coculture model with HT29-MTX cells could also be considered: ${ }^{44}$ HT29-MTX cells are able to secrete mucus, but the properties of the barrier (tight junctions, cytochromes, P-gp activity) are also different in comparison with Caco-2 cells used alone. For these reasons, we prefer to perform diffusion studies in mucus alone to study the diffusion without the effect of cell barrier properties that have been previously demonstrated. ${ }^{6}$ This work showed that LNCs improved Ptx diffusion through mucus.

The results of diffusion studies are strongly related to the methods used. In our study, the concentration was chosen to mimic in vivo conditions expected after conventional oral administration of Ptx. A similar protocol has been used previously by Norris and Sinko (same membrane and concentration in the same order of magnitude) to study the diffusion of polystyrene microspheres through gastrointestinal mucin. ${ }^{33}$ Because LNCs and Taxol ${ }^{\circledR}$ diffusion was lower than $3 \%$, the concentration was considered constant in each compartment. Diffusion was thus studied at the steady state, and so in the linear zone. That is also why no shaking could be applied. This had the advantage of respecting the mucus layer. Moreover, added mucus volume was lower than 5\% of both compartment volumes, and was thus considered negligible.

Diffusion is a very complex phenomenon including too many parameters to easily determine a real diffusion coefficient from the observed $P_{\text {app }}$.

LNCs were diluted by 44 - to 220 -fold. That is, the volumetric fraction ranged from $3 \times 10^{-3}$ to $6 \times 10^{-4}$. From these volumetric fractions, it is possible to determine that the statistical distance among LNCs was at least of two diameters, thus limiting their cross interaction in the diffusion process. 


\section{A}

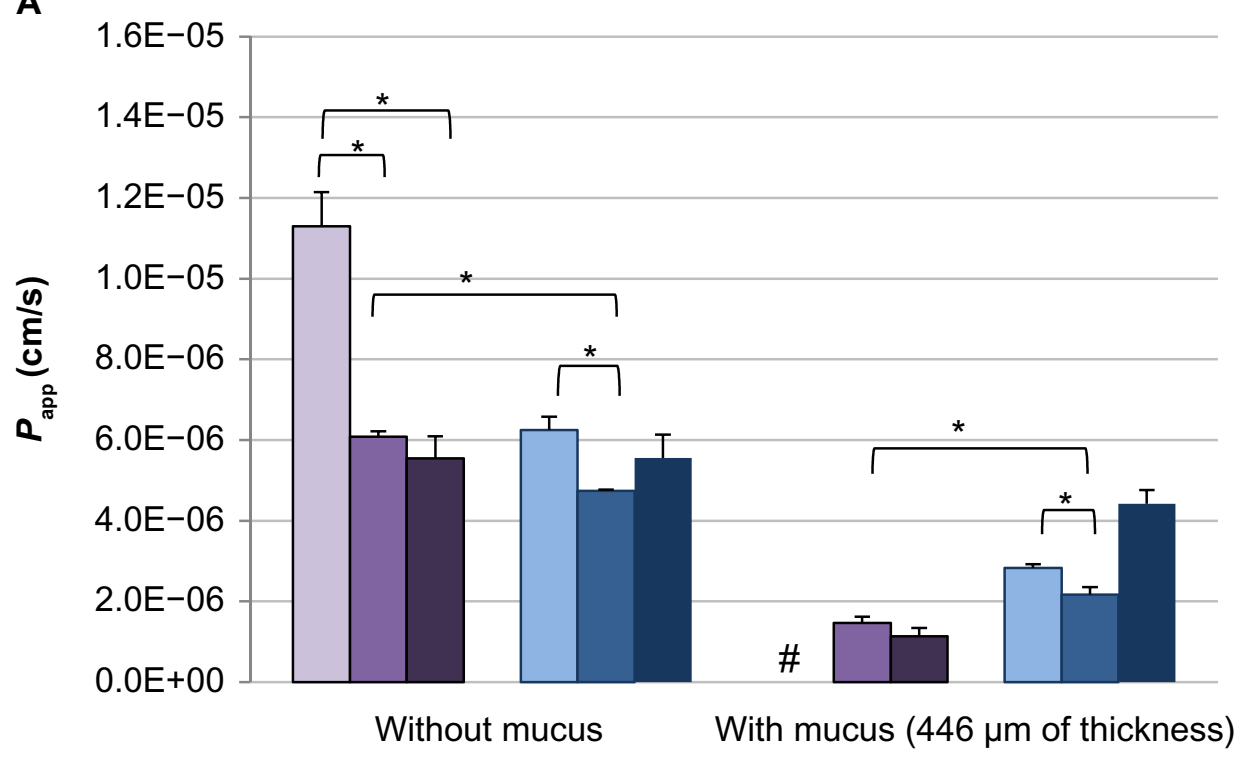

B

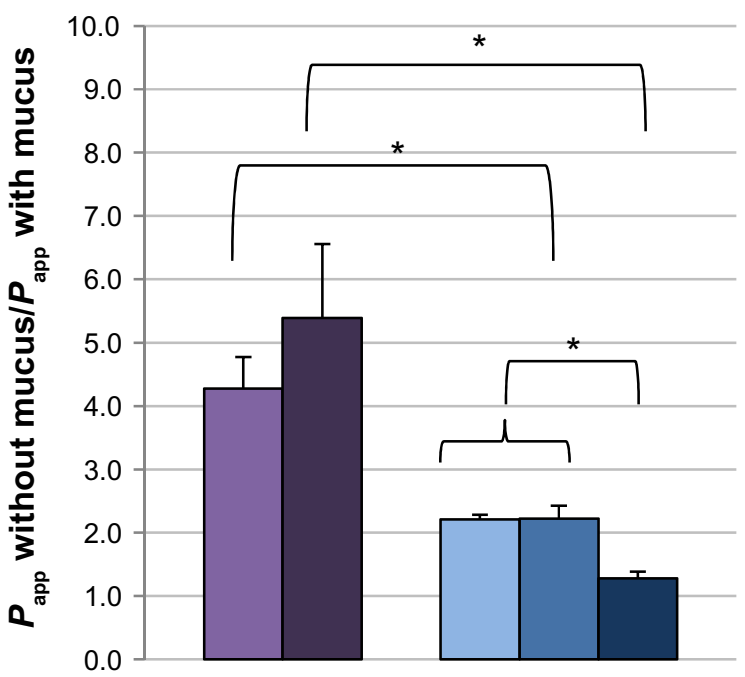

Figure 7 Diffusion after 2 hours of $55 \mathrm{~nm} \mathrm{LNCs}$ and Taxol ${ }^{\circledR}$ at different concentrations through Transwell ${ }^{\circledR}$ with mucus or without $(\mathbf{A})$. Effect of the mucus on LNC and

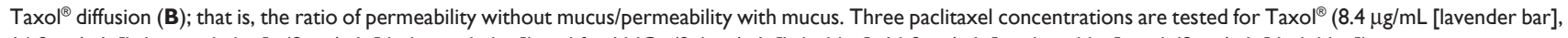
$16.8 \mu \mathrm{g} / \mathrm{mL}$ [light purple bar], $42 \mu \mathrm{g} / \mathrm{mL}$ [dark purple bar]) and for LNCs $(8.4 \mu \mathrm{g} / \mathrm{mL}$ [light blue], $16.8 \mu \mathrm{g} / \mathrm{mL}$ [medium blue], and $42 \mu \mathrm{g} / \mathrm{mL}$ [dark blue]).

Notes: Data are shown as mean \pm standard error of the mean $(n=3) ;{ }^{*}$ not quantifiable; $* P<0.05$.

Abbreviations: LNC, lipid nanocapsule; $P_{\text {app }}$, apparent permeability.

To choose optimal LNC sizes for diffusion, 3 different sizes of LNCs were prepared and tested: $110 \mathrm{~nm}$ LNCs were slowed down by the Transwell ${ }^{\circledR}$ membrane more than smaller LNCs. However, $110 \mathrm{~nm}$ LNCs had a different drug payload than other Ptx-loaded LNCs, but the diffusion ratio was much lower than for 25 and $55 \mathrm{~nm} \mathrm{LNC} \mathrm{diffusion.} \mathrm{This}$ difference in drug payload was not sufficient to explain this diffusion decrease. The polycarbonate membrane had $400 \mathrm{~nm}$ pore diameters, but an accessible diameter was calculated as a function of LNC diameters. The calculated accessible diameters for 25,55 , and $110 \mathrm{~nm}$ LNCs were 375,350 , and only $280 \mathrm{~nm}$, respectively. This smaller accessible diameter could explain the $110 \mathrm{~nm}$ LNC diffusion decrease through the Transwell ${ }^{\circledR}$ system without mucus. For these reasons, $110 \mathrm{~nm}$ LNC diffusion through mucus could not be compared with 25 or $55 \mathrm{~nm} \mathrm{LNC} \mathrm{diffusion.} \mathrm{In} \mathrm{contrast,} 25$ and $55 \mathrm{~nm}$ LNCs displayed the same diffusion through the Transwell ${ }^{\circledR}$ system, and their diffusion through the mucus could thus be compared. No size effect on diffusion through the mucus was found for these two sizes of LNCs. Average pore size diameters in mucus was previously found to be over $400 \mathrm{~nm},{ }^{45}$ so the fact that no size effect on diffusion was observed with our particles with a diameter smaller than $110 \mathrm{~nm}$ suggests they did not aggregate. No significant effect of size on LNC 
uptake in a range between 25 and $130 \mathrm{~nm}$ was shown in the Caco- 2 cell study. ${ }^{6}$ The increase of particle size from 25 to $100 \mathrm{~nm}$ increased complement activation. ${ }^{43}$ However, $25 \mathrm{~nm}$ LNCs quickly disappeared from the blood circulation. ${ }^{46}$ As a consequence, $55 \mathrm{~nm}$ LNCs were chosen for diffusion studies in a function of their concentration.

In diffusion studies described in the literature, the concentrations of the nanocarriers or the drug itself have been found to be highly variable. Sometimes the detection limit of the analytical technique is a determinant in the choice of the concentrations in the design of the experimental protocol. In our study, the detection limit was low (15 ng/mL) because LC/MSMS was used; three concentrations were tested to study whether diffusion was concentration dependent. These concentrations $(8.4,16.8$, and $42 \mu \mathrm{g} / \mathrm{mL})$ were slightly higher than the standard concentration $(4.2 \mu \mathrm{g} / \mathrm{mL})$ previously used on Caco-2 models to avoid modification of the cell barrier by the LNCs. At the highest concentration of LNCs, the ratio of $P_{\text {app }}$ without mucus over $P_{\text {app }}$ with mucus is close to one, demonstrating a good level of diffusion of LNCs in mucus at this concentration. This suggests a decrease of interaction between LNCs and mucus resulting from saturation. This study highlighted the importance of experimental conditions such as concentration on diffusion studies through mucus.

\section{Conclusion}

A toolbox to characterize the fate of colloids in mucus was developed. First, our mucus model was characterized. Pig intestinal mucus is a thixotropic, shear-thinning (nonNewtonian) gel, and its viscosity is hydration-dependent. The diffusion through the mucus and the stability of nanoparticles in this medium were then evaluated. These tools also allowed us to demonstrate that LNCs improved Ptx transport through the mucus layer in comparison to Taxol ${ }^{\circledR}$ and that LNCs were stable for 3 hours at $37^{\circ} \mathrm{C}$ after contact with mucus. These data also established that LNC sizes smaller than $110 \mathrm{~nm}$ did not influence diffusion but that concentration did. These new data confirm that LNCs are a suitable vector for oral delivery of biopharmaceutical classification system class IV drugs such as Ptx.

The next step is now to determine the physicochemical interactions between LNCs and mucus. Optimal surface properties of Ptx-loaded LNCs to improve Ptx apparent permeability through mucus remain to be determined.

\section{Disclosure}

Anne-Claire Groo is a fellow from Ethypharm supported by the Association Nationale de la Recherche et de la Technolo- gie. The other authors report no conflicts of interest in this work. The authors are grateful to ONIRIS for providing the source of the mucus.

\section{References}

1. Peltier S, Oger JM, Lagarce F, Couet W, Benoît JP. Enhanced oral paclitaxel bioavailability after administration of paclitaxel-loaded lipid nanocapsules. Pharm Res. 2006;23(6):1243-1250.

2. Heurtault B, Saulnier P, Pech B, Proust JE, Benoit JP. A novel phase inversion-based process for the preparation of lipid nanocarriers. Pharm Res. 2002;19(6):875-880.

3. Allard E, Huynh NT, Vessières A, et al. Dose effect activity of ferrocifen-loaded lipid nanocapsules on a 9L-glioma model. Int J Pharm. 2009;379(2):317-323.

4. Hureaux J, Lagarce F, Gagnadoux F, Clavreul A, Benoit JP, Urban T. The adaptation of lipid nanocapsule formulations for blood administration in animals. Int J Pharm. 2009;379(2):266-269.

5. Roger E, Lagarce F, Benoit JP. The gastrointestinal stability of lipid nanocapsules. Int J Pharm. 2009;379(2):260-265.

6. Roger E, Lagarce F, Garcion E, Benoit JP. Lipid nanocarriers improve paclitaxel transport throughout human intestinal epithelial cells by using vesicle-mediated transcytosis. J Control Release. 2009;140(2): 174-181.

7. Roger E, Lagarce F, Garcion E, Benoit JP. Reciprocal competition between lipid nanocapsules and P-gp for paclitaxel transport across Caco-2 cells. Eur J Pharm Sci. 11, 2010;40(5):422-429.

8. Lamprecht A, Benoit JP. Etoposide nanocarriers suppress glioma cell growth by intracellular drug delivery and simultaneous P-glycoprotein inhibition. J Control Release. 2006;112(2):208-213.

9. Morille M, Montier T, Legras P, et al. Long-circulating DNA lipid nanocapsules as new vector for passive tumor targeting. Biomaterials. 2010;31(2):321-329.

10. Roger E, Lagarce F, Garcion E, Benoit JP. Biopharmaceutical parameters to consider in order to alter the fate of nanocarriers after oral delivery. Nanomedicine (Lond). 2010;5(2):287-306.

11. Larhed AW, Artursson P, Gråsjö J, Björk E. Diffusion of drugs in native and purified gastrointestinal mucus. J Pharm Sci. 1997;86(6):660-665.

12. Lai SK, O'Hanlon DE, Harrold S, et al. Rapid transport of large polymeric nanoparticles in fresh undiluted human mucus. Proc Natl Acad Sci U S A. 2007;104(5):1482-1487.

13. Griffiths PC, Occhipinti P, Morris C, Heenan RK, King SM, Gumbleton M. PGSE-NMR and SANS studies of the interaction of model polymer therapeutics with mucin. Biomacromolecules. 2010;11(1): $120-125$.

14. Grübel P, Cave DR. Factors affecting solubility and penetration of clarithromycin through gastric mucus. Aliment Pharmacol Ther. 1998;12(6):569-576.

15. Hosseinzadeh H, Atyabi F, Dinarvand R, Ostad SN. Chitosan-Pluronic nanoparticles as oral delivery of anticancer gemcitabine: preparation and in vitro study. Int J Nanomedicine. 2012;7:1851-1863.

16. Larhed AW, Artursson P, Björk E. The influence of intestinal mucus components on the diffusion of drugs. Pharm Res. 1998;15(1):66-71.

17. Zabaleta V, Ponchel G, Salman H, Agüeros M, Vauthier C, Irache JM. Oral administration of paclitaxel with pegylated poly(anhydride) nanoparticles: permeability and pharmacokinetic study. Eur J Pharm Biopharm. 2012;81(3):514-523.

18. Agüeros M, Ruiz-Gatón L, Vauthier C, et al. Combined hydroxypropylbeta-cyclodextrin and poly(anhydride) nanoparticles improve the oral permeability of paclitaxel. Eur J Pharm Sci. 2009;38(4):405-413.

19. Jin Y, Song Y, Zhu X, Zhou D, Chen C, Zhang Z, Huang Y. Goblet cell-targeting nanoparticles for oral insulin delivery and the influence of mucus on insulin transport. Biomaterials. 2012;33(5):1573-1582.

20. Lesuffleur $T$, Barbat $A$, Luccioni $C$, et al. Dihydrofolate reductase gene amplification-associated shift of differentiation in methotrexate-adapted HT-29 cells. J Cell Biol. 1991;115(5):1409-1418. 
21. Lesuffleur T, Porchet N, Aubert JP, et al. Differential expression of the human mucin genes MUC1 to MUC5 in relation to growth and differentiation of different mucus-secreting HT-29 cell subpopulations. $J$ Cell Sci. 1993;106(Pt 3):771-783.

22. Meaney C, O'Driscoll C. Mucus as a barrier to the permeability of hydrophilic and lipophilic compounds in the absence and presence of sodium taurocholate micellar systems using cell culture models. Eur J Pharm Sci. 1999;8(3):167-175.

23. Walter E, Janich S, Roessler BJ, Hilfinger JM, Amidon GL. HT29-MTX/ Caco-2 cocultures as an in vitro model for the intestinal epithelium: in vitro-in vivo correlation with permeability data from rats and humans. J Pharm Sci. 1996;85(10):1070-1076.

24. Wikman-Larhed A, Artursson P. Co-cultures of human intestinal goblet (HT29-H) and absorptive (Caco-2) cells for studies of drug and peptide absorption. Eur J Pharm Sci. 1995;3(3):171-183.

25. Prego C, Fabre M, Torres D, Alonso MJ. Efficacy and mechanism of action of chitosan nanocapsules for oral peptide delivery. Pharm Res. 2006;23(3):549-556.

26. Behrens I, Pena AI, Alonso MJ, Kissel T. Comparative uptake studies of bioadhesive and non-bioadhesive nanoparticles in human intestinal cell lines and rats: the effect of mucus on particle adsorption and transport. Pharm Res. 2002;19(8):1185-1193.

27. Lundin PD, Bojrup M, Ljusberg-Wahren H, Weström BR, Lundin S. Enhancing effects of monohexanoin and two other medium-chain glyceride vehicles on intestinal absorption of desmopressin (dDAVP). J Pharmacol Exp Ther. 1997;282(2):585-590.

28. Jain S, Kumar D, Swarnakar NK, Thanki K. Polyelectrolyte stabilized multilayered liposomes for oral delivery of paclitaxel. Biomaterials. 2012;33(28):6758-6768.

29. Ezpeleta I, Arangoa MA, Irache JM, et al. Preparation of Ulex europaeus lectin-gliadin nanoparticle conjugates and their interaction with gastrointestinal mucus. Int J Pharm. 1999;191(1):25-32.

30. Bhat PG, Flanagan DR, Donovan MD. The limiting role of mucus in drug absorption: Drug permeation through mucus solution. International Journal of Pharmaceutics. December 29, 1995;126(1-2):179-187.

31. Shaw LR, Irwin WJ, Grattan TJ, Conway BR. The influence of excipients on the diffusion of ibuprofen and paracetamol in gastric mucus. Int J Pharm. 2005;290(1-2):145-154.

32. Bravo-Osuna I, Vauthier C, Chacun H, Ponchel G. Specific permeability modulation of intestinal paracellular pathway by chitosanpoly(isobutylcyanoacrylate) core-shell nanoparticles. Eur J Pharm Biopharm. 2008;69(2):436-444.
33. Norris DA, Sinko PJ. Effect of size, surface charge, and hydrophobicity on the translocation of polystyrene microspheres through gastrointestinal mucin. J Appl Polymer Sci. 1997;63(11):1481-1492.

34. McGill SL, Smyth HD. Disruption of the mucus barrier by topically applied exogenous particles. Mol Pharm. 2010;7(6):2280-2288.

35. Saltzman WM, Radomsky ML, Whaley KJ, Cone RA. Antibody diffusion in human cervical mucus. Biophys J. 1994;66(2 Pt 1): $508-515$.

36. Kowapradit J, Apirakaramwong A, Ngawhirunpat T, Rojanarata T, Sajomsang W, Opanasopit P. Methylated N-(4-N,N-dimethylaminobenzyl) chitosan coated liposomes for oral protein drug delivery. Eur J Pharm Sci. 29, 2012;47(2):359-366.

37. Chakravarthi SS, Robinson DH. Enhanced cellular association of paclitaxel delivered in chitosan-PLGA particles. Int $J$ Pharm. 2011;409(1-2):111-120.

38. Artursson P, Karlsson J. Correlation between oral drug absorption in humans and apparent drug permeability coefficients in human intestinal epithelial (Caco-2) cells. Biochem Biophys Res Commun. 1991;175(3): 880-885.

39. Artursson P, Borchardt RT. Intestinal drug absorption and metabolism in cell cultures: Caco-2 and beyond. Pharm Res. 1997;14(12): 1655-1658.

40. Larhed AW, Artursson P, Björk E. The influence of intestinal mucus components on the diffusion of drugs. Pharm Res. 1998;15(1):66-71.

41. Lai SK, Wang YY, Hanes J. Mucus-penetrating nanoparticles for drug and gene delivery to mucosal tissues. Adv Drug Deliv Rev. 2009;61(2): 158-171.

42. Cone RA. Barrier properties of mucus. Adv Drug Deliv Rev. 2009; 61(2):75-85.

43. Hirsjärvi S, Dufort S, Gravier J, et al. Influence of size, surface coating and fine chemical composition on the in vitro reactivity and in vivo biodistribution of lipid nanocapsules versus lipid nanoemulsions in cancer models. Nanomedicine. 2013;9(3):375-387.

44. Chen XM, Elisia I, Kitts DD. Defining conditions for the co-culture of Caco-2 and HT29-MTX cells using Taguchi design. J Pharmacol Toxicol Methods. 2010;61(3):334-342.

45. Broughton-Head VJ, Smith JR, Shur J, Shute JK. Actin limits enhancement of nanoparticle diffusion through cystic fibrosis sputum by mucolytics. Pulm Pharmacol Ther. 2007;20(6):708-717.

46. Hirsjärvi S, Sancey L, Dufort S, et al. Effect of particle size on the biodistribution of lipid nanocapsules: Comparison between nuclear and fluorescence imaging and counting. Int J Pharm. 2013;453(2):594-600.
International Journal of Nanomedicine

\section{Publish your work in this journal}

The International Journal of Nanomedicine is an international, peerreviewed journal focusing on the application of nanotechnology in diagnostics, therapeutics, and drug delivery systems throughout the biomedical field. This journal is indexed on PubMed Central, MedLine, CAS, SciSearch $\AA$, Current Contents ${ }^{\circledR} /$ Clinical Medicine,

\section{Dovepress}

Journal Citation Reports/Science Edition, EMBase, Scopus and the Elsevier Bibliographic databases. The manuscript management system is completely online and includes a very quick and fair peer-review system, which is all easy to use. Visit http://www.dovepress.com/ testimonials.php to read real quotes from published authors. 